\title{
Conn's Syndrome Secondary to Adrenal Adenoma
}

\author{
Sahil N. Fulara, Nasir Y. Fulara \\ Department of Medicine, Jaslok Hospital and Medical Research Center, Mumbai, India \\ Email: drsahil.fulara@gmail.com
}

How to cite this paper: Fulara, S.N. and Fulara, N.Y. (2016) Conn's Syndrome Secondary to Adrenal Adenoma. Open Journal of Clinical Diagnostics, 6, 47-51. http://dx.doi.org/10.4236/ojcd.2016.64009

Received: September 14, 2016

Accepted: October 29, 2016

Published: November 1, 2016

Copyright $\odot 2016$ by authors and Scientific Research Publishing Inc. This work is licensed under the Creative Commons Attribution International License (CC BY 4.0).

http://creativecommons.org/licenses/by/4.0/

\begin{abstract}
Primary hyperaldosteronism is not as uncommon as we thought, and by recent estimates the prevalance may be as high as $11 \%$ among hypertensives. We present a case of a 33 years old male patient came with a complaint of headache in occipital area \& weakness in both lower limb since 4 weeks. The patient was a diagnosed case of hypertension and was already on tablet Atenolol $(25 \mathrm{mg})$ once a day. At the time of admission, the patient was found to have a pulse of $96 / \mathrm{min}$ and blood pressure of $170 / 100 \mathrm{~mm}$ of $\mathrm{Hg}$. Power was $3 / 5$ for both right and left lower limbs. At the time of admission, serum potassium was 2.8 . As a result, the patient was shifted to tablet Metroprolol and Amlodipine $(50+5 \mathrm{mg})$ once a day. We also added tablet Cilnidipine $(10 \mathrm{mg})$ and Telmisartan $(80 \mathrm{mg})$ once a day and syrup Potklor thrice a day with water. The patient was sent for renal artery doppler, urine for metanephrines and vanillylmandelic acid, serum aldosterone, plasma aldosterone/plasma renin activity ratio (PAC/PRA ratio), urinary aldosterone, urinary cortisol and adrenocorticotrophic hormone level and computed tomography (CT) abdomen to rule out hyperaldostronism. Plasma aldosterone/plasma renin activity ratio, urinary aldosterone was high and CT abdomen revealed a solitary nodule in the left adrenal gland measuring $1.2 \times 1.0 \mathrm{~cm}$ in maximum transverse diameter, which was suggestive of adrenal adenoma. Diagnosis of Conn's syndrome secondary to adrenal adenoma was made. The patient was advised tablet Aldactone $(25 \mathrm{mg})$ once a day and serum electrolytes were repeated which showed normalization with normal blood pressure.
\end{abstract}

\section{Keywords}

Primary Hyperaldosteronism, Hypokalemia, Headache, Adenoma, Hypertension

\section{Introduction}

Primary hyperaldosteronism is more commonly recognized now than in the past. In older series, it was found in only $0.1 \%$ to $0.5 \%$ of hypertensive patients [1]. While the exact prevalence and significance of primary hyperaldosteronism in hypertension re- 
mains unclear, this is almost certainly an underestimate. Some studies have found primary hyperaldosteronism in up to $5 \%$ to $10 \%$ of hypertensive patients, and in patients with resistant or refractory hypertension, the prevalence may be as high as $11 \%$ to $23 \%$ [2]. Although primary aldosteronism is still a considerable diagnostic challenge, recognizing the condition is critical because primary aldosteronism-associated hypertension can often be cured (or at least optimally controlled) with the proper surgical or medical intervention. In this case report, we present a patient who presented with very nonspecific symptoms and was later diagnosed with Conn's syndrome.

\section{Case Report}

A 33-year old male patient came with a complaint of headache in occipital area \& weakness in both lower limbs since 4 weeks. Patient complained of headache in occipital area not associated with aura, nausea or vomiting. The patient did not complain of running of nose or blurred vision. The patient also complained of weakness in lower limb not associated with weakness of upper limb. No difficulty of speech, facial deviation was observed in the patient. The patient was able to perform daily activities. No evidence of bowel/bladder involvement was found in this patient. The patient had no history of diabetes mellitus/tuberculosis/hypertension in the past. The patient visited local doctor two weeks back where he was diagnosed with hypertension and was started on tablet Atenolol (25 mg) once a day. At the time of admission, the patient was found to have a pulse of $96 / \mathrm{min}$ and blood pressure of $170 / 100 \mathrm{~mm}$ of $\mathrm{Hg}$. On general examination, no pallor, clubbing, icterus or cyanosis was found. On systemic examination, no abnormalities were detected in the respiratory system, abdominal or cardiovascular system. On examining the central nervous system, power was $3 / 5$ for both right and left lower limbs. Power in rest of the limbs, tone, reflexes was normal. At the time of admission, the patient had deranged electrolytes, serum potassium was 2.8. As a result the patient was shifted to tablet Metroprolol and Amlodipine $(50+5 \mathrm{mg})$ once a day. We also added tablet Cilnidipine $(10 \mathrm{mg})$ and Telmisartan $(80 \mathrm{mg})$ once a day and syrup Potklor thrice a day with water (Table 1 ). The patient was sent for renal artery doppler and urine for metanephrines and vanillylmandelic acid. Renal doppler and urinary metanephrines failed to reveal any abnormality. In view of recurrent hypokalemia, the patient was advised to get serum aldosterone, plasma aldosterone/plasma renin activity ratio (PAC/PRA ratio), urinary aldosterone, urinary cortisol and adrenocorticotrophic hormone level. It was found that plasma aldosterone/plasma renin activity ratio and

Table 1. Electrolyte variations in the patient.

\begin{tabular}{cccccc}
\hline Patient variables & Day 1 & Day 3 & Day 5 & Day 7 & After starting Aldactone \\
\hline Sodium (mEq/L) & 144 & 141 & 143 & 141 & 138 \\
Potassium ( mEq/L) & 2.6 & 2.8 & 3.1 & 3 & 4.0 \\
Chloride (mEq/L) & 98 & 99.4 & 102 & 101 & 102 \\
Blood pressure (mm Hg) & $144 / 90$ & $138 / 86$ & $146 / 90$ & $144 / 92$ & $124 / 80$ \\
\hline
\end{tabular}


urinary aldosterone was high. As a result we decided to get a computed tomography (CT) of the abdomen to rule out hyperaldostronism (Table 2). CT abdomen revealed a solitary nodule in the left adrenal gland measuring $1.2 \times 1.0 \mathrm{~cm}$ in maximum transverse diameter, which was suggestive of adrenal adenoma (Figure 1). Diagnosis of Conn's syndrome secondary to adrenal adenoma was made. The patient was advised tablet Aldactone $(25 \mathrm{mg}$ ) once a day following which the serum electrolytes and blood pressure became normal. The patient was advised left sided adrenalectomy for long term benefit.

\section{Discussion}

The usual presenting features of primary aldosteronism are hypertension and hypo-

Table 2. Patient findings specific to primary hyperaldosteronism.

\begin{tabular}{cc}
\hline Cortisol $(8 \mathrm{am})$ & $10 \mathrm{mcg} / \mathrm{dl}$ \\
\hline Adrenocorticotropin & $21.30 \mathrm{pg} / \mathrm{ml}$ \\
Serum Aldosterone (Supine) & $98 \mathrm{ng} / \mathrm{dl}$ \\
Plasma Renin Activity & $0.06 \mu \mathrm{IU} / \mathrm{mL}$ \\
PA/PRA Ratio & 1638 \\
Urine Aldosterone & $35.5 \mathrm{mcg}$
\end{tabular}
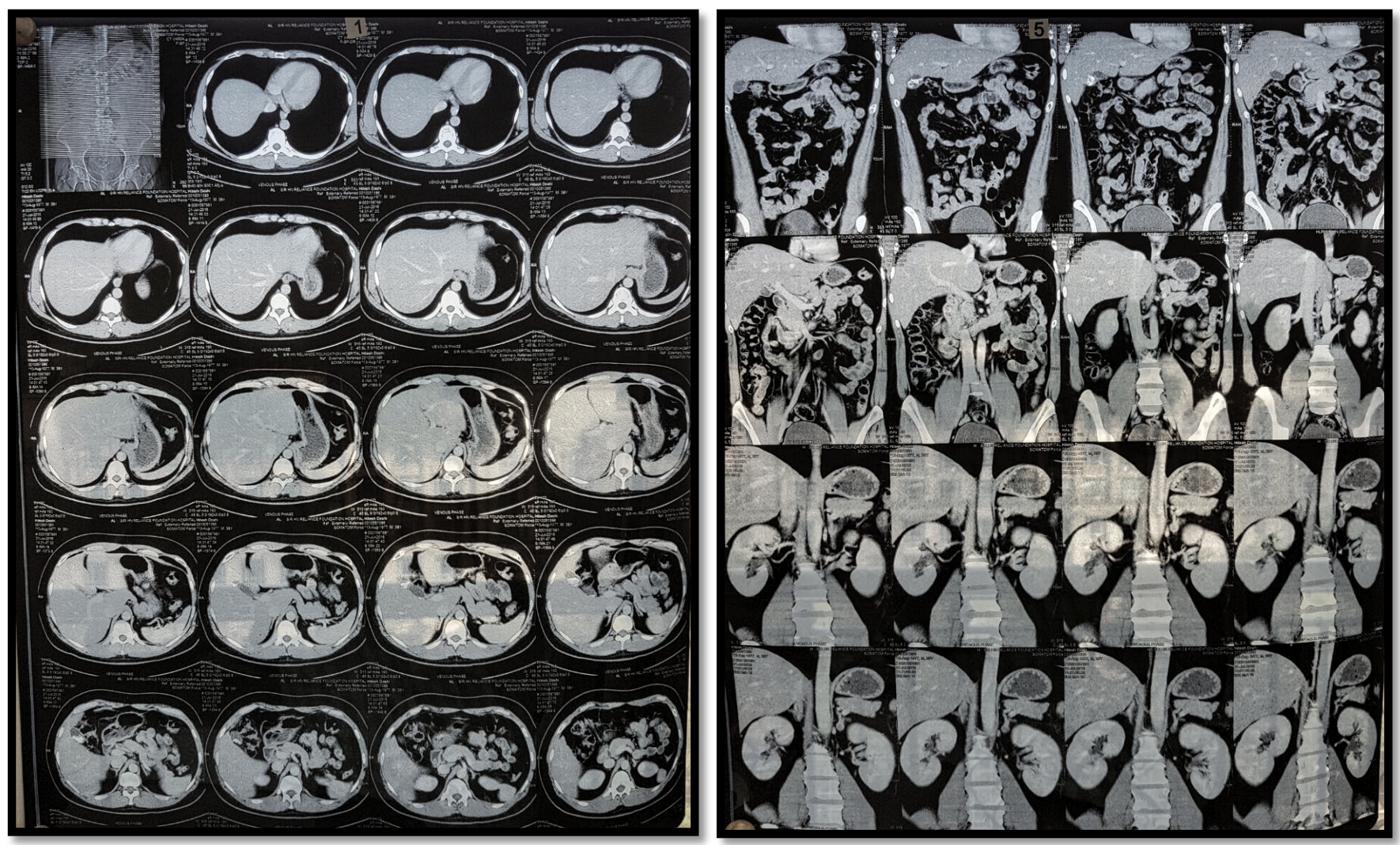

Figure 1. Computed tomography abdomen showing the adrenal adenoma. 
kalemia [3], but potassium levels are frequently normal in day to day cases of primary aldosteronism. It has been estimated that only $9 \%$ to $37 \%$ of patients with primary aldosteronism have low potassium levels. This is probably because of early diagnosis as more patients with hypertension are being screened for primary aldosteronism. The most common subtypes of primary aldosteronism are aldosterone-producing adenomas and bilateral idiopathic hyperaldosteronism. Less common forms of hyperaldosteronism includefamilial hyperaldosteronism, unilateral adrenal hyperplasia, pure aldosterone producing adrenocortical carcinomas andectopic aldosterone-producing tumors.

Very recently, the Endocrine Society updated their clinical practice guidelines for the diagnosis and treatment of primary aldosteronism [1]. The guidelines recommend case-detection testing in patient groups who have a relatively high prevalence of primary aldosteronism. However, there is evidence that the screening should include patients who havesystolic blood pressure higher than $150 \mathrm{mmHg}$ and diastolic blood pressure higher than $100 \mathrm{mmHg}$. Additionally, the guidelines stress the importance of a more timely diagnosis and treatment of such patients, given its high prevalence in hypertensives and its role in cardiovascular and kidney damage. While making the diagnosis it is also important to rule out other causes which might cause hypokalemia and hypertension, like renovascular disease (hypersecretion of renin leading to increased aldosterone secretion) and diuretic therapy. Less frequent causes are Cushing's syndrome, licorice ingestion, congenital adrenal hyperplasia, Liddle's syndrome, and reninsecreting tumors.

Diagnosis of primary aldosteronism requires a systematic approach. Case detection testing should be done in patients with severe or drug resistant hypertension, or hypertension with sleep apnea or patients who have a family history of early onset hypertension or cerebrovascular accident. It can be done using the ratio of plasma aldosterone concentration and plasma renin activity. Case confirmation can be done by oral sodium loading test. Further subtype classification requires more testing which may involve imaging.

In treating patients with primary aldosteronism we aim to prevent the morbidity and mortality associated with hypertension, hypokalemia, renal and cardiovascular damage. Excessive secretion of aldosterone is associated with an increased risk of cardiovascular events. Surgery is the preferred treatment for patients with unilateral disease. A marked reduction in aldosterone secretion and correction of the hypokalemia in almost all patients is seen after unilateral adrenalectomy [4]. Although laparoscopic adrenalectomy is more cost-effective, the administration of a mineralocorticoid receptor antagonist is an effective option in patients who refuse or are not candidates for surgery [5]. So in patients who refuse surgical options or are not fit to undergo one, the pharmacological treatment aims at correcting hypokalemia, normalizing the blood pressure, and reversing the effects of hyperaldosteronism on the heart. Of the mineralocorticoid receptor antagonists, spironolactone is suggested as the first-line drug and later switching to eplerenone if side effects are limiting [6]. Eplerenone is a more selective mineralocorti- 
coid receptor antagonist than spironolactone and is associated with fewer side effects.

\section{Conclusion}

Identifying primary aldosteronism is important because of its prevalence and association with a higher rate of cardiovascular morbidity and mortality when compared to age- and sex-matched patients with primary hypertension and the same degree of blood pressure elevation. We were able to diagnose this patient in a stepwise manner ruling out many diagnoses before arriving at the correct diagnosis. In patients diagnosed with primary aldosteronism, treatment of the mineralocorticoid excess results in reversal or improvement of the hypertension and resolution of the increased cardiovascular risk.

\section{References}

[1] Funder, J.W., Carey, R.M., Mantero, F., et al. (2016) The Management of Primary Aldosteronism: Case Detection, Diagnosis, and Treatment: An Endocrine Society Clinical Practice Guideline. The Journal of Clinical Endocrinology \& Metabolism, 101, 1889. http://dx.doi.org/10.1210/jc.2015-4061

[2] Douma, S., Petidis, K., Doumas, M., et al. (2008) Prevalence of PRIMARY hyperaldosteronism in Resistant Hypertension: A Retrospective Observational Study. The Lancet, 371, 1921. http://dx.doi.org/10.1016/S0140-6736(08)60834-X

[3] Mattsson, C. and Young Jr., W.F. (2006) Primary Aldosteronism: Diagnostic and Treatment Strategies. Nature Clinical Practice Nephrology, 2, 198-208.

http://dx.doi.org/10.1038/ncpneph0151

[4] Sawka, A.M., Young, W.F., Thompson, G.B., et al. (2001) Primary Aldosteronism: Factors Associated with Normalization of Blood Pressure after Surgery. Annals of Internal Medicine, 135, 258-261. http://dx.doi.org/10.7326/0003-4819-135-4-200108210-00010

[5] Ghose, R.P., Hall, P.M. and Bravo, E.L. (1999) Medical Management of Aldosterone-Producing Adenomas. Annals of Internal Medicine, 131, 105-108. http://dx.doi.org/10.7326/0003-4819-131-2-199907200-00005

[6] Riester, A. and Reincke, M. (2015) Progress in Primary Aldosteronism: Mineralocorticoid Receptor Antagonists and Management of Primary Aldosteronism in Pregnancy. European Journal of Endocrinology, 172, R23. http://dx.doi.org/10.1530/EJE-14-0444 
Submit or recommend next manuscript to SCIRP and we will provide best service for you:

Accepting pre-submission inquiries through Email, Facebook, LinkedIn, Twitter, etc. A wide selection of journals (inclusive of 9 subjects, more than 200 journals)

Providing 24-hour high-quality service

User-friendly online submission system

Fair and swift peer-review system

Efficient typesetting and proofreading procedure

Display of the result of downloads and visits, as well as the number of cited articles

Maximum dissemination of your research work

Submit your manuscript at: http://papersubmission.scirp.org/

Or contact ojcd@scirp.org 